\title{
Por UMA ESTÉTICA TÁTIL: SOBRE A ADAPTAÇÃO DE OBRAS DE ARTES PLÁSTICAS PARA DEFICIENTES VISUAIS ${ }^{\star}$

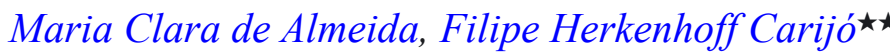 Virgínia Kastrup ${ }^{\star \star \star}$
}

\begin{abstract}
Resumo
Analisamos três estratégias comuns para se fornecer acesso às artes plásticas para deficientes visuais: adaptação via alto-relevo, uso representacional de texturas e seleção de esculturas. Lançando mão de estudos de psicologia cognitiva sobre tato (como GIBSON, 1962; LEDERMAN, 1997; HATWELL; MARTINEZ-SAROCCHI, 2000) discutimos tanto a adequação destas estratégias ao tato quanto seu alcance estético. Mostramos que a maioria das "versões táteis" nada possui de tátil: ignorando as propriedades cognitivas e a dimensão expressiva do tato, acabam por reproduzir padrões visuais. Concluímos que o acesso às artes plásticas deve ser pensado em termos da invenção de uma estética verdadeiramente tátil.
\end{abstract}

Palavras-chave: deficiência visual; percepção tátil; experiência estética; artes plásticas.

\section{TOWARDS A TACTILE AESTHETICS: ON THE ADAPTATION OF WORKS OF PLASTIC ART FOR THE VISUALLY DISABLED}

\begin{abstract}
Three common strategies for providing the visually disabled with access to plastic arts are analyzed: adapting works of art via raised-line techniques, using representational textures and selecting sculptures. We draw upon studies in the cognitive psychology of touch (such as GIBSON, 1962; LEDERMAN, 1997; HATWELL; MARTINEZ-SAROCCHI, 2000), in order to discuss both the adequacy of these strategies vis-à-vis the modality of touch and their aesthetic reach. We show that most "tactile versions" are by no means tactile: by ignoring both the cognitive properties and the expressive dimension of touch, they end up reproducing visual standards. We suggest that access to the plastic arts should be understood in terms of the invention of a truly tactile aesthetics.Keywords: visual disability; tactile perception; aesthetic experience; plastic arts.

\footnotetext{
^ Fontes de financiamento: CNPq e FAPERJ.

$\star \star$ Alunos do Curso de Graduação em Psicologia da Universidade Federal do Rio de Janeiro - UFRJ.

$\star \star \star$ Doutora em Psicologia e professora do Programa de Pós-Graduação em Psicologia da Universidade Federal do Rio de Janeiro - UFRJ. Endereço: Universidade Federal do Rio de Janeiro, Centro de Filosofia e Ciências Humanas, Departamento de Psicologia Geral e Experimental. Av. Pasteur, 250 - Pav. Nilton Campos - $2^{\circ}$ andar - Urca. CEP: 22290-240 - Rio de Janeiro, RJ - Brasil. E-mail: vkastrup@terra.com.br
} 
Keywords: visual disability; tactile perception; aesthetic experience; plastic arts.

\section{INTRODUÇÃO}

No Brasil e ao redor do mundo, proliferam as inciativas que visam dar acesso à arte às pessoas com deficiência visual: museus, galerias, oficinas de arte, curadores, artistas, educadores, arquitetos, o poder público e a iniciativa privada sentem a urgência de incluir, nos diferentes espaços em que a arte se manifesta, este público que, historicamente falando, sempre lhes foi um tanto estranho (SARRAF, 2008). Vemo-nos imersos num movimento inclusivo que se dissemina cada vez mais. Entretanto, apesar de os envolvidos terem, de maneira geral, bastante clareza a respeito da necessidade de se incluir o público deficiente, parecenos que ainda estamos muito longe de obter consenso sobre o que deve ser feito para realizar esta inclusão. Afinal de contas, as iniciativas inclusivas deparam-se com o fato, sedimentado ao longo da história, de que os museus e outros espaços de cultura são locais predominantemente destinados à exploração visual e, portanto, vedados à visitação de cegos quase que por definição. Mais problemática ainda é a constatação de que as próprias obras de arte, sobretudo quando se trata de artes plásticas, costumam ser feitas para serem vistas, e não tocadas, cheiradas, ouvidas etc. Surge então uma questão que ainda ecoa sem resposta definitiva: como possibilitar que cegos tenham acesso a algo tão visual como uma pintura, uma gravura ou uma escultura? Como viabilizar o acesso à estética visual?

Em circunstâncias assim complexas, é natural que surjam estratégias e posicionamentos os mais diversos. Vemos museus promoverem seminários sobre o tema, associações realizarem cursos, profissionais e artistas proporem as mais diversas estratégias, desde adaptações das obras de forma a torná-las acessíveis ao tato, passando pela disponibilização de audioguias que viabilizam a descrição verbal das peças, até a criação de peças originalmente destinadas à exploração tátil. Se, como observamos acima, o problema tem ares de intransponibilidade, ele é evidentemente uma oportunidade para que se deixe exercer a invenção nas mais diversas direções.

Neste contexto, uma prática que se tornou comum é a disponibilização de peças ao toque, tanto originais quanto adaptações. No entanto, isto muitas vezes é feito com pouca ou nenhuma consideração pela adequação das peças à percepção tátil, resultando em experimentações malsucedidas, que deixam confuso o espectador que se desejava incluir. Costuma-se simplesmente pressupor, por exemplo, que o alto-relevo e a escultura são formas de arte tão acessíveis ao tato quanto à visão. O objetivo do presente artigo é submeter a estratégia de disponibilização de peças ao toque a uma análise crítica, partindo de considerações cognitivas sobre o funcionamento do tato, buscando apontar suas potencialidades e seus limites como modalidade perceptiva. Sugerimos, contra a tendência ainda dominante, que o melhor caminho para a inclusão não é reproduzir, para o tato, uma estética visual, mas aproveitar uma tendência já existente e encorajar o desenvolvimento de uma estética tátil autônoma. Trata-se, como veremos, de recolocar a questão do acesso à estética visual em novos termos. 


\section{Algumas distinções importantes}

Para abordar a questão com todo o rigor, parece-nos que seria preciso, antes de mais nada, fazer notar algumas nuanças, muitas vezes ignoradas, que perpassam a questão do acesso à arte. Em primeiro lugar, convém distinguir o acesso ao espaço do acesso às obras. Embora esta distinção pareça evidente, ainda é preciso lembrar que o acesso ao espaço é condição necessária para o acesso às obras, mas não suficiente. $\mathrm{O}$ acesso ao espaço é uma questão arquitetônica, mas também de transporte e de criação de programas de visitação (como excursões, por exemplo). Ele é mais básico, no sentido de que é o primeiro passo em direção a uma inclusão verdadeira. No entanto, ele não é o bastante. De que adiantaria permitir aos deficientes visuais a plena autonomia de circulação e mobilidade no museu, se não lhes proporcionássemos igualmente o acesso às obras de arte? O próprio sentido da visita a um museu de arte estaria perdido. Apesar de ser evidente que o propósito primeiro de se visitar um museu geralmente é o contato com as obras, o que se constata é que a discussão a respeito do acesso ao espaço encontra-se atualmente muito mais bem desenvolvida que a discussão sobre o acesso às obras. Em alguns casos extremos, a discussão sobre o acesso ao espaço chega a ofuscar a discussão sobre o acesso às obras, mesmo entre educadores. Para os deficientes visuais, no entanto, a discussão sobre o acesso ao espaço não é tão importante quanto para cadeirantes, por exemplo, já que, para os cegos, a dificuldade de locomoção é pouco ou nada impeditiva quando comparada à inacessibilidade das obras.

É preciso traçar ainda uma segunda distinção importante. Mesmo nas vezes em que se discute o acesso à obra, nem sempre está claro se o propósito da inciativa inclusiva é proporcionar acesso "informativo" ou um acesso propriamente "estético" (cf. HATWELL; MARTINEZ-SAROCCHI, 2000). Ter clareza a respeito deste ponto é importante, porque uma tal decisão determina práticas e políticas inclusivas diferentes. $\mathrm{O}$ acesso informativo pode a princípio ser resolvido com relativa simplicidade através da descrição verbal da obra em questão, por exemplo, via audioguia, textos em braille ou pela presença de um mediador. É uma tendência recente nas iniciativas inclusivas, porém, que elas tenham alguma pretensão estética, ainda que não declarada. Assim, vemos os museus disponibilizarem peças ao toque, tanto réplicas quanto originais. Mas, no caso de optarmos pelo acesso estético, é preciso ainda que nos perguntemos se as estratégias são adequadas. Afinal de contas, o simples ato de disponibilizar peças ao toque não garante, por si só, a solução ao problema do acesso estético; é preciso ainda saber se as peças oferecidas se prestam à apreciação tátil. E, como veremos, é comum oferecer ao toque obras que o tato, enquanto sistema perceptivo, nem sempre é capaz de apreender. Na verdade, muitas destas obras e adaptações, por desconsiderarem o funcionamento próprio do sistema tátil (muitas vezes tomando-o equivocadamente como análogo ao da visão), acabam por retirar as próprias condições de uma percepção dotada de sentido estético. 


\section{As DifERENTES ESTRATÉGias de ADAPTAÇÃo}

Quando se investigam as iniciativas inclusivas nos diferentes espaços (museus, escolas, livros de arte), identificam-se três formas básicas de apresentação das obras. Primeiramente, observamos uma forte tendência a se utilizar a técnica do alto-relevo, tanto para a reprodução de pinturas e gravuras clássicas quanto para a produção de material original, feito especialmente para o público cego. Uma segunda estratégia é a exposição de esculturas, tanto reproduções quanto peças originais, disponibilizando-as ao toque. Uma terceira alternativa para a adaptação de pinturas e gravuras para o tato é o uso representacional de texturas, fazendo cada uma delas representar uma cor ou uma parte diferente da obra. Todas estas estratégias permitem que o público explore as obras através do tato, pretendendo dar aos cegos o mesmo acesso às obras de artes plásticas de que dispõem os videntes. A seguir, analisamos separadamente cada uma destas estratégias.

\section{O ACESSo PELO Alto-Relevo}

A primeira ideia que costuma surgir, quando alguém se depara com a questão de como adaptar uma pintura ou um desenho de modo a torná-los acessíveis a pessoas com deficiência visual, é a de reproduzi-los em alto-relevo. A princípio, esta solução parece natural e adequada, pois torna as formas acessíveis à ponta dos dedos. De maneira geral, o alto-relevo é tomado como o correlato tátil natural de obras bidimensionais: de um conjunto de linhas visuais, faz-se um conjunto de linhas táteis. Se é verdade que neste processo de adaptação se perde a cor, a forma - e com ela o conteúdo representacional da obra - pareceria estar preservada. Assim, a estratégia da adaptação pelo alto-relevo é muitas vezes recebida pelos museus como um instrumento de inclusão genuíno.

Um dos exemplos mais representativos desta proposta é a exposição Raised Awareness, ocorrida no Tate Modern, em Londres, 2005. Celebrada pelo Times Online como um evento que, finalmente, transformava a arte para os cegos em realidade (IRVING, 2005), a mostra reuniu obras de diversos artistas, feitas especialmente para a exposição. As obras eram desenhos feitos à tinta já com o objetivo de, em seguida, serem reproduzidos em alto-relevo. As duas versões da obra - a tátil e a visual - eram expostas lado a lado. Ao visitante era dado explorar, então, obras que representavam desde paisagens como uma praia, até objetos aparentemente mais acessíveis à exploração tátil, como uma mão. Era ainda possível ouvir uma gravação para cada obra, que descrevia a peça e explicava a intenção do artista. Assim, esperava-se que os cegos pudessem ter uma compreensão de obras que não eram apenas adaptações, mas se pretendiam genuinamente táteis, já que feitas especialmente para este sentido. ${ }^{1}$

Este é apenas um exemplo dentre as muitas tentativas de dar acesso a obras de arte através do uso de relevo. Note-se aqui o caráter figurativo das obras, ou seja, o fato de que se pretendem representações de objetos ou coisas concretas. Isto faz com que o desenho em relevo tenha, antes de qualquer coisa, a função específica de remeter àqueles objetos e coisas ali representados, não se tratando 
de elementos abstratos. Não podemos deixar de reconhecer um certo mérito em se experimentar formas de acesso aos deficientes visuais a obras de arte através dessas iniciativas. Tais adaptações pressupõem, entretanto, que o tato seja capaz de interpretar o alto-relevo. Porém, como veremos a seguir, este não parece ser o caso na maioria das vezes.

O principal problema das reproduções em alto-relevo talvez seja o fato de que, apesar de replicarem os quadros numa forma tangível, elas mantêm, apesar disso, sua forma visual. O alto-relevo geralmente pressupõe, por exemplo, que o percebedor domine as regras de transposição de formas em três dimensões para duas dimensões (HATWELL; MARTINEZ-SAROCCHI, 2000). Ocorre que estas regras são visuais, fazendo pouco ou nenhum sentido para o tato. Exemplifiquemos isto através do exame de uma das obras que compunha a mencionada exposição do Tate Modern: Ship in a bottle, de Bill Woodrow (Fig. 1).



Fig. 1: Ship in a bottle, Bill Woodrow, 2003

A obra mostra as duas mãos de uma pessoa segurando uma garrafa transparente em posição horizontal - a mão esquerda sustenta a base e a direita a tampa da garrafa. Dentro da garrafa, flutuando sobre um pouco de água que há no fundo, há um navio a vela de brinquedo. Ao fundo da cena vê-se o oceano, cujo limite com o céu é indicado por uma única e distante linha horizontal. Sobre o mar flutua um navio também distante. No canto superior direito, vê-se o sol, que aparece como um pequeno disco; no inferior direito, vê-se parte de um precipício. Tudo leva o espectador a crer que a pessoa cujas mãos seguram a 
garrafa (e que não aparece na obra) encontra-se diante de um precipício e que a cena toda é retratada tal como ela a vê. Além disso, o observador parece erguer a garrafa de forma a mirar seu conteúdo.

Ora, esta obra não apresenta maiores ambiguidades perceptivas para o espectador que a explora com a visão. Para o observador tátil, no entanto, a lista de possíveis confusões é longa. O que o observador cego deve fazer, por exemplo, com o fato de que a mão representada no quadro parece dezenas de vezes maior do que o navio ao fundo, ou, aliás, muito maior do que o precipício à direita? Isto, que não parece estranho para quem automaticamente lança mão das regras da perspectiva visual, cria enormes confusões para aquele que explora através do tato. Ou ainda, como decifrar as muitas sobreposições ao longo da gravura - mão sobre garrafa, garrafa sobre navio de brinquedo, mão sobre oceano? Como distinguir os muitos planos que ela apresenta? Como identificar o começo da mão e o fim da garrafa? Como reconhecer que a face esquerda do precipício está banhada em sombra?

Hatwell e Martinez-Sarocchi (2000) observam que objetos representados em duas dimensões se parecem muito mais com os objetos reais, tais como percebidos pela visão, do que como percebidos pelo tato. Aliás, como mostram os autores, a própria produção de desenhos em relevo por pessoas cegas, munidas de material apropriado, coloca em evidência algumas dificuldades. ${ }^{2}$ E comum que o desenho feito por pessoas cegas se apresente de forma tal que todos os lados do objeto sejam representados ao mesmo tempo. O tato parece não aceitar esta transposição para duas dimensões à qual a visão se presta, insistindo em permanecer um sentido das três dimensões.

Esta característica tridimensional do tato já havia sido observada por Gibson (1962). Numa atividade experimental em que os sujeitos não podiam ver o que tinham nas mãos, Gibson pediu que explorassem livremente alguns objetos. Ele notou que, nessas condições, alguns padrões de exploração se repetiam. Em primeiro lugar, os sujeitos tendiam a tocar os objetos com as duas mãos. Os dedos geralmente se curvavam ao redor do objeto e se moviam de maneira complexa. Alguns destes movimentos foram registrados como mais frequentes, como: fazer movimentos com um ou mais dedos ao redor do objeto; utilizar o dedo polegar em oposição aos demais dedos; fazer movimentos para pressionar, agarrar e esfregar o objeto com os dedos. Além disso, Gibson notou que os dedos dos sujeitos prontamente tendiam às arestas e aos vértices, explorando antes de mais nada a geometria 3D dos objetos. Estas observações apontam para um traço de tridimensionalidade intrínseco à própria exploração manual. A curvatura dos dedos, o uso de duas mãos para agarrar, a oposição do dedo polegar em relação aos outros evidenciam uma busca de elementos espaciais específicos na exploração natural de objetos com as mãos. Na exploração manual livre de um objeto, os sujeitos nunca se limitam ao mero alisar bidimensional das superfícies ou faces, mas buscam sempre sua geometria tridimensional - vértices, arestas, curvaturas. Ora, quando pedimos a alguém que explore uma figura em alto-relevo, pedimos que se limite a alisar uma superfície. Assim, restringimos o próprio funcionamento do sistema háptico, ${ }^{3}$ visto que, de cada objeto representado, apresentamos apenas uma face. Em outras palavras, retiramos uma das condições essenciais da percepção háptica de objetos. 
Além disso, sem as indicações tridimensionais, que funcionam como uma espécie de guia da direção da exploração manual, a pessoa cega pode sentir-se um pouco perdida. Ao encontrar uma bifurcação ou um encontro de muitas linhas numa placa de alto-relevo, em que direção deve seguir explorando? Isto não é um problema para a visão, que não encontra dificuldades em distinguir as linhas que compõem um emaranhado. No domínio tátil, no entanto, um emaranhado bidimensional é algo confuso, aparecendo antes como uma espécie de borrão indefinido.

Outras evidências experimentais se acumulam contra a possibilidade de se acessar desenhos em alto-relevo de maneira satisfatória. Lederman (1997) mostra que a percepção deste tipo de desenho através do tato geralmente é muito pobre, lenta e imprecisa, além de estar sujeita a inúmeras distorções. Numa série de experimentos sobre a percepção tátil de figuras em alto-relevo, Lederman et al. (1990) vendaram sujeitos videntes e pediram-lhes que explorassem desenhos em alto-relevo de objetos comuns. Buscando eliminar vieses indesejados, as autoras selecionaram objetos que na vida real possuem tamanho tal que possam ser explorados facilmente pelas mãos (uma cenoura, por exemplo, seria elegível, mas não um cavalo). Os resultados mostraram que mesmo esses desenhos de objetos pequenos e acessíveis foram identificados em apenas 33,5\% das vezes. Além disso, verificou-se que os sujeitos recorriam a imagens mentais para identificar as figuras, utilizando-se de memória visual. O mesmo experimento foi repetido com pessoas cegas congênitas. Os resultados foram drasticamente piores: apenas $10,4 \%$ de acertos. Os experimentos mostraram que o reconhecimento de figuras em alto-relevo geralmente é mais bem-sucedido quando se recorre a uma espécie de tradução visual dos estímulos hápticos, estratégia de que os cegos congênitos estão privados. Como já apontamos, a representação de objetos em alto-relevo se utiliza de indicações visuais, como perspectiva e sobreposição, às quais o tato não dá acesso. Lederman et al. (1990) afirmam que este tipo de projeção não é natural para cegos congênitos, que aprenderam a explorar hapticamente tais objetos em suas três dimensões, com livre manipulação deles no espaço. Assim, estas autoras concluem que os desenhos bidimensionais limitam o sistema háptico, cujo campo de exploração parece compreender movimentos mais complexos e características tridimensionais.

Um último comentário merece ser feito sobre o acesso ao alto-relevo do ponto de vista do tato enquanto sistema perceptivo. Quando na vida cotidiana reconhecemos um objeto pelo tato, temos a impressão de que a propriedade determinante para o reconhecimento é a sua forma. Mas essa impressão pode estar equivocada. Segundo Klatzky e Lederman (1995), ${ }^{4}$ quando se trata de reconhecer objetos, o tato depende muito mais de qualidades materiais - como textura, peso e dureza - do que o senso comum nos faria suspeitar. Um único e breve contato manual com um objeto cotidiano pode, se permitir a apreensão de sua textura, possibilitar seu reconhecimento, mesmo que não seja suficiente para a apreensão de sua forma global. Ao contrário do que ocorre com a visão, o tato avalia muito mais rapidamente as propriedades materiais dos objetos do que suas propriedades formais (KLATZKY et al., 1987) $)^{5}$ e, por isso, reconhece-os fazendo muito mais apelo a essas qualidades do que à visão. ${ }^{6}$ Identificar o reconhecimento do objeto 
com o reconhecimento de sua forma é pensar a percepção em termos visuocêntricos; na identificação de objetos, o tato parece guiar-se de maneira significativa por pistas não formais. Ora, quando representamos objetos através do alto-relevo, deixamos registrada tão somente sua forma, privando-os, precisamente, de sua qualidade material. No alto-relevo, todos os objetos desenhados aparecem portando as mesmas propriedades materiais - não as dos próprios objetos, mas a do material de que é feita a placa de alto-relevo. Isto, que não atrapalha a apreciação visual, contribui para tornar improvável sua fruição pelo tato.

Somos, portanto, levados a concluir que o alto-relevo, longe de transformar uma pintura num objeto próprio para a apreciação tátil, mantém seu caráter essencialmente visual. O alto-relevo não é uma versão tátil da obra, mas “outra" versão visual. Donde se conclui que, para pessoas cegas, especialmente para aquelas que nunca viram, um desenho em alto-relevo dificilmente faz sentido. Parece então que a criação ou adaptação de obras em alto-relevo não é a maneira mais apropriada de dar acesso às obras de arte às pessoas cegas, como naturalmente se supõe. Ao contrário, o que podemos esperar é que a obra em alto-relevo, em si mesma, cause mais confusão do que inclusão para os cegos. É provável que, sem a ajuda de um mediador ou sem uma explicação em braille, o acesso a tais obras permaneça completamente inviável. A adaptação em alto-relevo não parece provocar experiência estética, porque na maioria das vezes o percebedor não é nem mesmo capaz de entender o que lhe é oferecido. Na ausência de uma explicação verbal, a adaptação em alto-relevo pode frustrar mesmo a expectativa de fornecer informação sobre a obra.

Levantemos a ressalva, no entanto, de que estes resultados não devem necessariamente levar-nos a abandonar a proposta de fornecer acesso estético às artes plásticas bidimensionais. Trata-se apenas de enfatizar que o alto-relevo não parece a melhor alternativa. Tampouco temos motivos para crer que seja a única. Como dissemos anteriormente, estamos diante de um problema que, se não possui solução óbvia, por isso mesmo instaura um desejo de criar e constitui uma oportunidade de experimentar em novas direções.

\section{O ACESSO PELA TEXTURA REPRESENTACIONAL}

Aproveitar aquilo que é próprio do tato é o que buscam as estratégias que se valem da textura para produzir "imagens táteis" bidimensionais. A ideia é de que, se é possível pintar com cores, também deve ser possível "pintar" com texturas. Particularmente, deve ser possível adaptar uma pintura ao se fazer uma textura diferente corresponder a cada cor, ou - como ocorre num outro uso desta técnica - ao se fazer cada textura corresponder a uma parte diferente de um objeto. A técnica conhecida como swell paper, por exemplo, combina o alto-relevo com este uso representacional de texturas (RIEDEL; BURTON, 2001).

Esta estratégia tem o mérito de buscar aquilo que o tato tem de potencialidade. Uma de suas vantagens é a de não condenar o tato à percepção da pura forma, como faz o alto-relevo, tornando disponível também uma qualidade material - a textura. Mesmo assim, a técnica apresenta problemas. O primeiro deles é compar- 
tilhado com o alto-relevo: a transposição das três dimensões para as duas é algo estranho para o tato. É de se esperar, portanto, que a confusão decorrente desta transposição também se manifeste aqui. A principal limitação da estratégia, porém, é que o "significado" atribuído a cada textura é totalmente artificial. Apresentam-se texturas, mas não para que sejam apreciadas enquanto texturas; elas estão ali para servir de via de acesso alternativo à cor. Nessa estratégia, o sentido expressivo próprio das texturas não é explorado. Se seu objetivo é potencializar o que o tato possui de próprio, o espectador pode ficar a se perguntar como se pretende atingi-lo ao se utilizar texturas como instrumento de representação de cores.

Paralelamente a este problema corre um outro, que é o de saber "para quê" as texturas apontam, já que se referem a algo distinto delas mesmas. Este uso representacional das texturas não possui nada de intuitivo, não sendo claro de antemão o que as texturas "querem dizer". Decorre que, sem a ajuda de algum tipo de código convencionado especialmente com este propósito, a fruição da obra se torna inviável. Este problema se torna ainda maior quando consideramos que os cegos congênitos - uma parcela considerável do público para quem as adaptações são feitas - estão, de saída, impossibilitados de compreender plenamente uma tal linguagem artificialmente criada, já que o referente (a cor) está para além do campo de sua experiência.

O uso de texturas pode ser um passo em direção à inclusão artística, mas é importante perceber que não é todo e qualquer uso de texturas que nos aproxima da realização de um acesso dotado de sentido estético. Parece-nos que, quando (implícita ou explicitamente) convencionamos um tal código, optamos por fornecer apenas um acesso informacional, preterindo a possibilidade de um acesso estético. $\mathrm{Na}$ melhor das hipóteses, uma estratégia como a aqui descrita pode, quando acompanhada de uma explicação verbal, fornecer informação sobre a obra em questão ("aqui está o mar, aqui fica o céu”).

Finalmente, assim como no caso do alto-relevo havíamos verificado que as adaptações não logram fazer a obra passar do domínio visual para o domínio tátil, também aqui a proposta segue por demais referenciada na visão. Afinal, o próprio objetivo é representar cores através de texturas. Se a textura - objeto da percepção tátil - comparece, não é por seu sentido expressivo próprio, mas para representar aquilo que é objeto da visão. A estratégia introduz o tato com uma mão para retirá-lo com a outra.

\section{O ACESSO Às ESCULTURAS}

A escultura é, ao lado do alto-relevo, a maneira mais comum de se buscar viabilizar o acesso dos deficientes visuais à obra de arte. Afinal de contas, uma escultura é inegavelmente um objeto tangível. Daí a ideia de que seja um objeto artístico apreciável tanto pelo tato quanto pela visão, sem necessidade alguma de adaptação, a não ser em casos de esculturas de grandes dimensões ou de materiais danificáveis pelo toque. Deixando de lado toda a problemática em torno da preservação das peças em face do toque, que não discutiremos aqui, ${ }^{7}$ seria, a 
princípio, razoável acreditar que a escultura é uma forma de arte tão tátil quanto visual. Assim, é comum que os museus destinem esculturas para a apreciação pelo tato, sejam elas reproduções ou originais.

De fato, as esculturas não padecem do problema comum ao alto-relevo e ao uso representacional de texturas - a bidimensionalidade estranha ao tato. As esculturas, pelo contrário, permitem ao percebedor buscar concavidades e convexidades, vértices, arestas, faces e outras indicações tridimensionais. Neste sentido pelo menos, elas não restringem o sistema háptico da exploração manual. No entanto, apesar de parecer uma solução natural, a exposição de esculturas acaba por restringir o tato de outras maneiras, como veremos à frente.

$\mathrm{Na}$ discussão sobre a disponibilização de esculturas para o toque é instrutivo recordar a contribuição de Révész (1950), que foi um dos primeiros a se perguntar pela possibilidade de se apreciar tatilmente uma obra esculpida em pedra. Ele acreditou - como se costuma crer intuitivamente - que se o tato pudesse ter alguma participação na esfera das artes plásticas, essa participação teria que se dar necessariamente por meio da escultura. Ainda que possamos questionar tal pressuposto, é necessário reconhecer que Révész produziu questões importantes e inaugurou toda uma linha de investigações. Para esclarecer a questão, o autor preparou um experimento. O design é simples: pede-se a sujeitos cegos congênitos que explorem bustos esculpidos em pedra e que relatem o que estão percebendo à medida que exploram. Começa-se por mostrar um busto do jovem Nero a um cego "instruído". Após uma breve exploração háptica, o sujeito declara tratar-se do busto de um homem velho, apontando que apenas um velho traria rugas na testa. Mas não se trata absolutamente disso: o busto é Nero ainda criança, e as supostas rugas são na verdade mechas de cabelo. Outro cego recebe o busto de uma moça florentina. Por causa do cabelo, arrumado de maneira diferente da usual, infere tratar-se de um busto do demônio. Um outro explora o busto de Homero e, a princípio, reconhece aí uma mulher. É apenas quando descobre a barba que o sujeito muda de ideia, sem nunca, porém, ser capaz de reconhecer a expressão facial. Depois, pede-se a uma mulher cega que explore dois bustos idênticos, salvo pela diferença de que um é mais bem acabado que o outro. Ela percebe um casal onde, na verdade, há dois homens. Os exemplos se multiplicam. Révész mostra que o mesmo fato ocorria quando os sujeitos cegos eram substituídos por videntes vendados. E, ainda quando os sujeitos eram escultores videntes que haviam tido contato visual prévio com os bustos, os resultados permaneciam os mesmos. A partir dos resultados de seus experimentos, Révész conclui (muito apressadamente, a nosso ver) que o tato está excluído da esfera estética. Ora, esta conclusão não se segue aos dados obtidos. Apesar de as contribuições deste autor serem muito originais e da maior importância para o campo, suas conclusões gerais acerca do potencial estético do tato são amplamente questionáveis - é preciso fazer uma leitura crítica de seu Psychology and art of the blind. Seus resultados, no entanto, são bastante reveladores no que tange à apreciação tátil de esculturas. Perguntamos: que hipóteses podemos levantar para entender esta aparente incapacidade do tato de decifrar bustos em pedra? 
Kilgour e Lederman (2002) realizam um estudo experimental que pode ser esclarecedor. Num primeiro momento, pedem a videntes vendados que explorem com as mãos o rosto de uma outra pessoa. Em seguida, pedem que explorem três rostos e digam qual dos três é o mesmo que exploraram anteriormente. Quando o experimento é realizado nessas condições, a taxa de acerto é alta: $78,9 \%$. Em seguida repete-se todo o procedimento, com a diferença de que desta vez, em vez de rostos reais, utilizam-se máscaras de barro. A taxa de acerto cai significativamente: $58,9 \%{ }^{8}$ Assim, vemos mais uma vez a importância das propriedades materiais para a percepção tátil; afinal, as máscaras de barro utilizadas no experimento são idênticas aos rostos humanos no que tange à forma, mas não no que tange ao material.

A escultura, que possui a vantagem de ser tridimensional, porta a limitação do material. Sem dúvida, a escultura possui textura, dureza, temperatura, e assim por diante. Mas estas são próprias do material de que a obra é feita (bronze, mármore, resina etc.), e não do objeto figurado. Como consequência, a escultura pode condenar o tato a uma espécie de percepção da pura forma, em que as qualidades materiais apareceriam como meros acidentes. Ora, é preciso notar que aquilo que parece acidental, e mesmo secundário de um ponto de vista visual, pode tornar-se uma importante contradição na esfera tátil.

O que acaba de ser dito poderia ter como consequência imediata a própria impossibilidade de se representar objetos por meio de materiais diferentes daquele do qual o objeto é feito; para representar cabelos, teríamos que oferecer não pedra talhada em forma de cabelos, mas os próprios cabelos; para representar madeira, não teríamos escolha senão utilizar madeira. Nada que não possuísse as mesmas propriedades materiais serviria. Em última análise, isto excluiria por completo a possibilidade da plena apreciação tátil de uma escultura.

Mas não se trata disto. Em primeiro lugar, mesmo as peças feitas sem nenhuma atenção a este problema permitem, sim, alguma apreciação estética pelo tato: muitos deficientes visuais relatam apreciar esculturas. Isto, que pode ser interpretado como uma manifestação do espírito pouco crítico de alguns deficientes visuais, ${ }^{9}$ também pode ser entendido como a prova de que a escultura "pode" se prestar bem à apreciação tátil. Até agora não temos motivos para crer que, para representar determinado material, devemos apresentar "exatamente" aquele material. Longe disso, o que já sabemos é apenas que representar objetos através de materiais completamente diferentes daqueles de que são feitos - utilizar pedra para uma túnica, como no exemplo de Hatwell e Martinez-Sarocchi (2000) - pode deixar o percebedor tátil diante de um confuso labirinto perceptivo, preso a uma tarefa de reconhecimento sem fim. Ora, condenar o sujeito a uma indecifrável tarefa recognitiva é não deixá-lo livre para a apreciação estética de tais obras.

O que importa é fazer um uso do material que seja dotado de sentido. É essencial perceber que, assim como a arte visual compõe com formas e cores, sem que a cor apareça de maneira puramente aleatória, mas sempre portando um sentido estético, também na arte destinada ao tato é preciso, analogamente, 
não utilizar o material de maneira acidental, e sim realizar composições, atentando sempre aos seus efeitos perceptivos, ainda que agora se trate de compor com formas e materiais.

Um último ponto a ser comentado sobre o uso de esculturas para inclusão artística é o fato, também relatado por alguns cegos, de que o tato parece sujeito a uma espécie de fadiga quando se exploram esculturas, ainda que estas sejam simples e de pequenas dimensões. Não é incomum notar, em exposições inclusivas, que alguns cegos parecem cansar-se relativamente rápido, após a exploração de algumas poucas peças, perdendo o interesse pelas obras. Podemos nos perguntar se não estamos, mais uma vez, diante de um problema ocasionado pela carência material das esculturas: retiradas certas condições da percepção tátil (as propriedades materiais dos objetos), o tato ficaria mais propenso à saturação. Trata-se de uma hipótese para mais uma questão que exige investigação e inventividade.

\section{Conclusão}

Quando visamos incluir os deficientes visuais em espaços de arte, como museus e galerias, defrontamo-nos com o inconveniente de que as obras exibidas são, com raras exceções, feitas apenas para serem vistas. Se não nos contentamos em fornecer um acesso meramente informacional, mas buscamos proporcionar experiências genuinamente estéticas, surge o desafio de tornar as obras acessíveis ao tato. A estratégia de disponibilizar peças para o toque é uma excelente proposta, mas as maneiras mais comuns de implementá-la portam o grave problema de, inadvertidamente, continuar oferecendo ao tato um percepto que é mais adequado à visão. Buscamos demonstrar que este problema surge quando se lança mão do alto-relevo e quando se faz um uso representacional de texturas, além de também manifestar-se na disponibilização de esculturas, originais ou reproduções simplificadas. O problema não é apenas que essas iniciativas falhem em reproduzir com exatidão as obras originais, mas que, muitas vezes, acabem por produzir obras que um percebedor tátil possui pouca chance de apreciar.

Será que as iniciativas inclusivas se propõem a dar acesso a algo que, afinal de contas, é esteticamente inacessível? Teremos, então, que dizer que os cegos, no terreno das artes plásticas, devem contentar-se com uma experiência estética de segunda mão? Não há razão para acreditar nisso. Se aquilo que aparece como o caminho mais simples para a inclusão é questionável, nem por isso devemos concluir que o acesso estético é impossível. O relativo fracasso dessas iniciativas decorre, em parte, de uma desconsideração dos aspectos próprios do tato e, em parte, de um arraigamento excessivo a padrões estéticos visuais.

Neste ponto alguém poderá objetar: mas nosso objetivo não era, desde o início, fornecer acesso à estética visual? A esta pergunta é preciso responder: sim e não. O que uma estratégia inclusiva deve fazer não é apenas alterar a mídia, o veículo material da obra. Acima de tudo, deve-se recriar a obra de arte. Ao se propor a adaptar um romance para o cinema, o cineasta sabe que o livro não será transportado, ponto a ponto, para a tela. O que se tem pela frente não é um trabalho de reprodução; é um esforço de reinvenção. O romance e o filme, ainda 
que possuam a narrativa como estrutura comum, dispõem de recursos técnicos e estéticos radicalmente diferentes. O cinema não é um mero recurso para aqueles que não sabem ler. Pela tradução cria-se forçosamente uma estética nova, e um cineasta que não se preocupasse em fazer nada mais que manter a estética original faria um mau filme. Ora, assim como a literatura e o cinema possuem dinâmicas próprias, também visão e tato são muito diversos em seus recursos e em sua dimensão expressiva. É preciso admitir que, desde o início, a questão esteve mal colocada; não se trata apenas de dar acesso à estética visual, porque não se pode fazer do tato um sentido transparente, como uma lente através da qual fosse possível enxergar as obras visuais. Ele não se presta ao papel de transmissor invisível - possui suas próprias exigências. Nosso verdadeiro problema não é, portanto, o acesso à estética visual, mas a criação e a disponibilização de uma estética tátil.

Explorar o que é próprio do tato, buscar sua contribuição estética única - algo já recomendado por autores como Lowenfeld (1951) e Arnheim (1990) - é o caminho que já começam a tomar algumas produções artísticas contemporâneas. A arte contemporânea tem extrapolado a estética puramente visual, revelando a plena possibilidade da criação de uma arte tátil sólida, deixando evidente que, inclusive no que concerne às adaptações, há um amplo campo ainda a ser explorado. No Brasil, por exemplo, a artista plástica Adrianna Eu produziu uma peça original, intitulada Guarda-chuva, composta de um guarda-chuva aberto cujo tecido foi homogeneamente perfurado por inúmeros alfinetes com o lado pontiagudo projetado para o interior. $\mathrm{O}$ expectador a princípio crê que os alfinetes serão desagradáveis ao toque, mas eis que o conjunto das pontas dos alfinetes oferece uma textura agradável. E o mais interessante é que esta textura remete imediatamente à chuva. Ao tocar a peça, sentimos a textura da chuva. $\mathrm{O}$ mérito da obra não provém apenas do prazer sensorial proporcionado pela textura. A verdadeira experiência estética é deflagrada pelo sentido novo e inesperado que a textura adquire. É por esta propriedade que a peça se torna uma obra de arte tátil. Outro exemplo interessante é a peça Espelho Cego, de Cildo Meireles. Uma moldura de pequenas dimensões, preenchida com uma espécie de massa de modelar, é disponibilizada não apenas para a exploração tátil, mas também para a interação: cada espectador é convidado a modificar a peça, modelando-a através do toque. Esta obra tematiza um aspecto específico da exploração manual, que é o de afetar o próprio objeto tocado.

Vemos assim que o tato, por sua própria complexidade, oferece aos artistas inúmeras possibilidades e direções de criação, o que já aparece em algumas produções contemporâneas. Cabe inventar novas maneiras de produzir sentido estético tanto através da forma quanto da textura, do peso e das propriedades materiais em geral. Só assim será possível, finalmente, abandonar os padrões estéticos puramente visuais que impregnam as artes plásticas, permitindo-nos criar e recriar obras de arte de uma maneira mais condizente com o modo de perceber das pessoas cegas. $\mathrm{O}$ respeito pelo universo cognitivo das pessoas cegas não implica, como às vezes se pensa, numa restrição do campo estético, mas em sua ampliação. 


\section{Notas}

${ }^{1}$ Mais informações disponíveis no site: http://www.tate.org.uk/modern/exhibitions/ raisedawareness.

${ }^{2}$ Para um ponto de vista contrário ao de Hatwell e Martinez-Sarocchi, ver Kennedy (2003).

${ }^{3} \mathrm{O}$ termo háptico refere-se à exploração tátil ativa, sobretudo manual, em oposição ao tato passivo (GIBSON, 1962).

${ }^{4}$ Para uma revisão, ver Klatzky e Lederman (2000).

${ }^{5}$ Segundo experimentos conduzidos por Klatzky e Lederman (1995), um contato de apenas 200 milissegundos pode ser suficiente para a apreensão da textura e para a identificação do objeto.

${ }^{6}$ Para outros resultados experimentais que apóiam essa conclusão, ver Lederman et al. (1986, 1990).

${ }^{7}$ Para uma discussão sobre este problema, ver Candlin (2004, 2006).

${ }^{8}$ Estas taxas podem parecer relativamente altas, quando contrastadas com os resultados de Révész, mas de fato não há inconsistência entre os dois estudos. É preciso levar em conta que o estudo de Révész exigia dos sujeitos o reconhecimento e a descrição dos bustos, uma tarefa muito mais difícil do que aquela exigida dos sujeitos por Kilgour e Lederman.

${ }^{9}$ Candlin $(2004,2006)$ observa que os cegos muitas vezes se mostram acríticos em relação ao serviço que lhes é oferecido pelos museus.

\section{REFERÊNCIAS}

ARNHEIM, R. Perceptual aspects of art for the blind. Journal of Aesthetic Education, [S.1.], v. 24, p. 57-65, 1990.

CANDLIN, F. Don't touch! Hands off! Art, blindness and the conservation of expertise. Body \& Society, [S.1.], v. 10, n. 1, p.71-90, 2004.

CANDLIN, F. Dubious inheritance of touch: art history and museum access. Journal of Visual Culture, [S.1.], v. 5, n. 2, p.137-154, 2006.

GIBSON, J. J. Observations on active touch. Psychological Review, [S.1.], v. 69, p. $477-490,1962$.

HATWELL, Y.; MARTINEZ-SAROCCHI, F. La lecture tactile des cartes et dessins et l'accès des aveugles aux oeuvres d'art. In: HATWELL, Y.; STRERI, A.; GENTAZ, E. (Ed.). Toucher pour connaître: psychologie cognitive de la peception tactile manuelle. Paris: Presses Universitaires de France, 2000. p. $267-$ 286.

IRVING, M. Art for the Blind Becomes Reality. Times online, Londres, 13 julho, 2005. Disponível em: http://entertainment.timesonline.co.uk/tol/arts_and entertainment/article543182.ece. Acesso em: 3 jul. 2009.

KLATZKY, R. et al. There's more to touch than meets the eye: the salience of object attributes for haptics with and without vision. Journal of Experimental Psychology: General, v. 116, n. 4, p. 356-369, 1987.

KLATZKY, R., LEDERMAN, S. Identifying objects from a haptic glance. 
Perception \& Psychophysics, [S.1.], v. 57, n. 8, p. 1111-1123, 1995.

KLATZKY, R., LEDERMAN, S. L'identification haptique des objets significatifs. In: HATWELL, Y.; STRERI, A.; GENTAZ, E. (Ed.). Toucher pour connaître: psychologie cognitive de la peception tactile manuelle. Paris: Presses Universitaires de France, 2000. p. 109-128.

KENNEDY, J. M. Drawings from Gaia, a blind girl. Perception, [S.1.], v. 32, p. 321-340, 2003.

KILGOUR, A.; LEDERMAN, S. Face recognition by hand. Perception \& Psychophysics, [S.1.], v. 64, n. 3, 2002, p. 339-352.

LEDERMAN, S. Skin and touch. In: San Diego: Academic Press, 1997. v.7, p. 51-63.

LEDERMAN, S. etal.Perceptionoftexturebyvisionandtouch:multidimensionality and intersensory integration. Journal of Experimental Psychology: Human Perception \& Performance, [S.1.], v. 12, n. 2, p.169-180, 1986.

LEDERMAN, S. et al. Visual mediation and the haptic recognition of twodimensional pictures of common objects. Perception \& Psychophysics, [S.1.], v. 47, n. 1, p. 54-64, 1990.

LOWENFELD, V. Psycho-aesthetic implications of the art of the blind. Journal of Aesthetics and Art Criticism, [S.1.], v. 10, n. 1, p. 1-9, 1951.

RÉVÉSZ, G. Psychology and art of the blind. New York: Longmans Green, 1950 .

RIEDEL, B., BURTON, A. M. Perception of Gradient in Haptic Graphs: a Comparison of Virtual and Physical Stimuli. Eurohaptics 2001 Conference Proceedings, 2001. p.90-92.

SARRAF, V. Reabilitação do Museu: políticas de inclusão cultural por meio da acessibilidade. 2008. Dissertação (Mestrado em Ciência da Informação)Universidade de São Paulo, São Paulo, 2008.

WOODROW, B. Ship in a bottle. 2003. 1 desenho. Disponível em: $<$ http://www. tate.org.uk/modern/exhibitions/raisedawareness/woodrow.htm>. Acesso em: 15 jul. 2009.

Recebido em: agosto de 2009

Aceito em: fevereiro de 2010 
